\title{
7
}

\section{Social Mechanisms Governing the Informal Transactions between Russian IT Managers}

While the previous chapter dealt with the contents of Russian managers' informal transactions (e.g. information, advice, money), this chapter describes the social mechanisms regulating these transactions. Instead of trying to cover all such mechanisms, the chapter focuses on reciprocal obligations, brokerage, and mixing of professional and personal spheres of life, that is, mechanisms that are supposed to create continuity in relationships and enlarge personal networks by introducing new members. ${ }^{1}$

\section{Reciprocal expectations in Russian managers' transactions}

The norm of reciprocity vs. the importance of socializing

It seems natural to think that a given favor evokes an expectation of a counter favor, thus contributing to the maintenance of the network tie. In his article The Norm of Reciprocity: A Preliminary Statement (1960), sociologist Alvin Gouldner explains this expectation by the existence of a universal, generalized norm of reciprocity. ${ }^{2}$ Gouldner considers reciprocity to be as universal and important in cultures as the incest taboo, though he admits that its 'concrete formulations' may vary according to time and place. ${ }^{3}$ Moreover, the norm may also differ within one society according to the status of participants or certain other conditions. Gouldner also mentions how the norm may function differently to some degree in different cultures, and also leaves room for the lack of reciprocal obligations:

Relations with little or no reciprocity may, for example, occur when power disparities allow one party to coerce the other. There may also be special mechanisms which compensate for or control the tensions 
which arise in the event of a breakdown in reciprocity. Among such compensatory mechanisms there may be culturally shared prescriptions of one-sided or unconditional generosity, such as the Christian notion of 'turning the other cheek' or 'walking the second mile', the feudal notion of 'noblesse oblige', or the Roman notion of 'clemency'.

(Gouldner 1960: 164)

Edwina Uehara (1995) notes that the formulation of Gouldner's norm is very general. In actual interaction situations, people have to make concrete decisions about, among other things, how much, when, and how to reciprocate

[O]ur expectations as to how and when we can 'legitimately' meet our reciprocity obligations are quite diverse, and some relationships afford more flexibility in this regard than others. For example, in relationships where indirect and/or delayed reciprocity is permitted, we are afforded a relatively wide degree of latitude in meeting reciprocity obligations.

(Uehara 1995: 487)

We asked about the existence of reciprocal expectations and their actual realizations in concrete interaction situations among our Russian respondents with the help of two questions. The first question considered the possibility of a 'free lunch', and the other the possibility of an unreciprocated favor. The English expression 'there's no such thing as a free lunch' was translated into the Russian saying 'there is free cheese only in a mouse trap' (besplatnyi syr tol'ko v myshelovke). ${ }^{4}$

In general the respondents admitted that doing a favor for someone created a need for a counter favor:

Q: There is a saying 'there is free cheese only in a mouse trap.' To what extent do you agree with this?

P4: Basically, of course, I agree. If someone does you a favor, you suppose as a silent agreement that you are ready to do some kind of a reciprocal favor. If not now, then in the future. In my opinion these are normal human relations (eto normal'nye chelovecheskie otnosheniia)

(general director, $\mathrm{p} 4$ )

Some of the respondents, however, disputed the whole principle by criticizing the barter logic inherent in our question (and in Gouldner's 
norm). Instead, they related the giving of favors to a broader process of obshchenie - building and maintaining personal networks through communicating and socializing:

Q: Generally when you do someone a favor or someone does you a favor, do you expect something in return?

P6: No, I don't. If I do a favor, I don't do it on the basis of barter. But I have noticed that very often some contacts will overlap. They probably won't bring concrete results right away, but perhaps later. But this is similar to human communication (srodni chelovecheskomu obshcheniiu). I am not giving you an interview because I expect something in return. Absolutely not. I give you an interview because it won't take me much time. I can grant you half an hour. If this helps you, as I understand, why not?

(marketing director, p6)

This quote echoes the words of Luc Boltanski in a recent interview (Basaure 2008). Boltanski noted how expecting no reciprocity might seem like an unreachable ideal but 'I think in daily life it happens very often, because it would become completely impossible, if anyone would constantly calculate what he is doing and what is being done for him, as equivalencies must permanently be evoked' (Basaure 2008: 7, translated by M. L.).

The quote may be interpreted as a criticism of the economic-rational perspective implied in the question, which considers the individual act of exchange as abstracted from its actual context. The reciprocal expectations do not, for this respondent, figure as a motive for action or relate to individual actions but rather to the nature of the ongoing 'human communication' (cf. Gronow 2008). In a similar manner, another of our respondents (general director, p4) justified his helping others out without reciprocation as 'normal human communication' (normal'noe chelovecheskoe obshchenie).

Alexey Yurchak (2006: 148-51) has paid attention to the importance of obshchenie, which has no adequate equivalent in English:

It refers to 'communication' and 'conversation', but in addition involves nonverbal interaction and spending time together or being together. It is different from just 'hanging out' with friends, as used in the United States, because it always involves an intense and intimate commonality and intersubjectivity, not just spending time in the company of others. The noun obshchenie has the same root as obshchii 
(common) and obshchina (commune), stressing in the process of interaction not the exchange between individuals but the communal space where everyone's personhood is dialogized to produce a common intersubjective sociality. Obshchenie, therefore, is both a process and a sociality that emerges in that process, and both an exchange of ideas and information as well as a space of affect and togetherness.

(Yurchak 2006: 148)

Quoting Vail and Genis (1988: 69), Yurchak (2006: 148) notes how obshchenie as a cultural practice intensified and evolved into a dominant pastime during late socialism. Though he remarks that in present day Russia people are regretting the diminishing chances for obshchenie, our interviews testify to its continuous existence and importance.

Indications of the importance of this practice were the frequent cases of obshchenie that took place not only among the Russian IT professionals, but also between our native Russian interviewer and the respondents. The interviewer was advised to record her observations about the respondent and the interview situation on tape after each interview session. As a result, our 'meta-level data' of the interviewer-interviewee encounters contain several instances of the following type:

[The respondent was a] very sociable (obshchitel'nyi) person. The conversation took place in the office. The respondent offered me coffee and introduced me to his partner. After the interview we still talked about some topics that were of interest t0o both of us. For example, the respondent has a very wide circle of sociality (krug obshcheniia).

(interviewer's comment on the interview with general director, p3)

This quote illustrates not only an encounter between two individual persons, but a coupling of two personal networks (krug obshcheniia) through the commonly shared practice of socializing and communicating. Note that the interviewer uses the word 'conversation' (beseda) in addition to 'interview'. The conversation ended with the respondent's invitation to the interviewer to join his personal network on a social networking website. Despite the time constraints of our respondents, these kinds of instances of socializing took place frequently after the formal interview had ended:

During the conversation after the interview it became clear that the respondent is studying English and has been in English courses abroad. He regretted not being able to talk 'kitchen English' because 
of the lack of occasions to practice. During the informal conversation after the interview we moved to a first-name basis (my pereshli na ty), and talked about the respondent's relationship to the city.

(interviewer's comment on the interview with development director, p5)

The importance of obshchenie was also key to understanding the interviews: our Western interview questions about the importance of reciprocating a given favor were often answered with examples emphasizing the importance of obshchenie. Metaphorically speaking, when asked if a person donating seeds to a gardener would expect a counter gift, many respondents suggested that it was more important to communicate and socialize with the gardener. The contact established might or might not bear fruit in the future:

I presume that if I help someone, I can also turn to this person with some questions. But I do not think at all that there is some kind of unavoidable principle of equality, some kind of calculation like 'I helped you once, you will help me later'.

(development director, $\mathrm{p} 17$ )

Many respondents agreed with the norm of reciprocity in principle but nevertheless told several examples of favors they had done without expecting something in return. First, some examples of unreciprocated favors considered cases where resources had been distributed so unevenly between the participants of the exchange that both understood that reciprocity was not an option (cf. Ledeneva's 'regime of status', 1998: 150-2):

Sometimes I can do a favor understanding that I will never get anything back. Because the person, for example, cannot give me anything.

(PR manager, p19)

Second, the respondents analyzed various factors related to situational contexts affecting reciprocal expectations:

I don't know why you should necessarily do others a favor in order to be able to ask for one. If I ask you to bring me a cup of coffee, what reasons do you have to refuse?

Q: None

P5: You can bring it. This is an example. If it is not difficult and does not require a lot of work. You just do it. Another variant is that you 
have no reason to refuse but you feel lazy. And you will say that I do not feel like it. This will also be a variant of communication (eto tozhe budet variantom obshcheniia) (...) A wish is simply a wish and not a command. One cannot count on that what you want will be done. But one can hope for it.

(development director, p5)

Third, several respondents stressed the dependency of the reciprocal expectations on the nature of the relationship. According to them, friendship relations, for example, had different rules than business relations in terms of reciprocity (see the end of this chapter for a more detailed account on friendship):

Q: They say that there is free cheese only in a mouse trap. If you do someone a favor, you will expect something in exchange, some kind of help or favor. Do you agree with this saying?

P13: No I don't. It does not work in friendship relations ( $v$ druzheskikh otnosheniiakh). In them everything is different, otherwise they would not be friendship relations but something completely different.

(general director, p13)

In sum, although the majority of the respondents agreed with Gouldner's norm of reciprocity in principle, many told examples of situations where they themselves had given help without expecting to be reciprocated; some denied it altogether; and others refined the norm in several respects, pointing to, among other things, the importance of obshchenie. Even a professional encounter between the interviewer and the interviewee could be transformed into a coupling of their personal networks through obshchenie.

These denials and variations of the norm of reciprocity suggest that, in addition to reciprocal obligations, other social and moral mechanisms were at work in the personal networks of our respondents. In the next section the denials of reciprocity are discussed based on Alena Ledeneva's (1998) work on the 'Russian economy of favours' already addressed in the previous sections.

\section{Denials of reciprocity as misrecognition}

Ledeneva (1998: 141) analyzes reciprocal obligations in blat exchanges in a manner that is relevant to the current study. According to her, the particular nature of blat favors has an impact on reciprocal expectations since it can be located between gift and commodity exchanges. On the 
one hand, blat favors are different from commodity exchanges because they bear the personal stamp of the donor, but on the other hand blat favors may also be distinguished from gift exchanges because they happen upon request. Consequently, blat is protected from the 'compulsion of the gift' and imposed generosities.

To find a way to deal with the complexity of reciprocal obligations in blat exchanges, Ledeneva (1998: 142-4) refers to Luc Boltanski's distinction between the 'affective regime' and the 'regime of justice'. To summarize Ledeneva's presentation, which draws on Luc Boltanski's lecture at Princeton in 1992: in the 'regime of justice' parties search for equivalencies - or a common point of reference - to manage disputes whereas in the 'affective regime' people shove aside all calculations of equivalencies. ${ }^{5}$

Based on the theorizing of Boltanski and Thévenot, Ledeneva herself constructs three different 'regimes of reciprocity': the regime of equivalence, the regime of affection, and the regime of status, between which the exchange partners may switch depending on the situation. In the regime of equivalence, the reciprocal expectations are most explicit since the focus is on the potential utility of the exchange partner. In the regime of affection participants stress the relationship itself rather than counter favors, and are bound by personal ties irrespective of their involvement in blat transactions. Finally, unlike the two other regimes, the regime of status is asymmetrical and can follow the pattern of patron-client relationships. This regime is affected by the status, power, and authority of the participants in blat exchanges and shows how reciprocal expectations may be irrelevant since some favors cannot be paid back even in principle (Ledeneva 1998: 142-52).

While Ledeneva's trichotomy sheds light on various aspects of the reciprocity of blat exchanges, it also contains problems, since elsewhere in her book she analyzes blat transactions with the help of Pierre Bourdieu's notion of misrecognition (méconnaissance) in gift transactions. According to Bourdieu, the temporal delay between the gift and the counter-gift enables parties to create an illusion of the non-reciprocal nature of the gift. In reality, the reciprocal obligations do exist, and only the collective participation in the 'misrecognition game' makes it possible to conceal this objective fact.

In blat exchanges, however, the misrecognition game was incomplete, because people were able to recognize an exchange of favors as blat when it was conducted by others, but unable to do this when they were themselves involved in blat transactions:

The complexity of the blat 'misrecognition game' cannot be fully grasped by Bourdieu's concept of misrecognition, where even being 
outside of the gift exchange transaction, a member of a community would admit that it is a gift that has been given. As not all individuals accept the internal rhetoric of blat and recognise it indicates that this did not endanger the foundation of community - that is, there was no universally shared sense of 'honour' involved in blat.

(Ledeneva 1998: 59-60; see also Ledeneva 2008: 129-30)

The disclosing of the objective truth underneath the respondents' discourse in the misrecognition game seems to be at odds with the theory of Boltanski and Thévenot (2006), according to which ' $[t]$ he regime in which one makes calculations is no more true, no more real, than the regime in which people inhibit their calculation abilities'. However, according to Ledeneva - who illustrates this regime mainly with examples of friendship ties - in the regime of affection 'the feelings of affection disguise blat relations' and 'the rhetoric of friendship tends to conceal mutual obligations' (Ledeneva 1998: 148-9). If these mutual obligations are not obeyed, the real state of affairs is revealed:

But in fact, if the balance in the relationship is broken, if one takes offence and feels that the code of friendship has been violated, the relationships are likely to slip into the regime of equivalence.

(Ledeneva 1998: 149)

In other words, it looks as if in Ledeneva's trichotomy the regime of affection would be a somewhat unstable discursive layer, under which the 'objective reality' of reciprocal obligations is to be found - as in Bourdieu's misrecognition game.

\section{Denials of reciprocity as references to shared moral principles}

Instead of applying the notion of misrecognition to denials of reciprocity, this section follows the lead opened by Luc Boltanski and Laurent Thévenot (2006) in their book On Justification. Economies of Worth ([1991], 2006). ${ }^{6}$ From this perspective, the respondents' reflections on reciprocity may be considered ways of justifying their actions by referring to shared moral principles.

Our respondents' appeal to moral principles in the interviews concerning their professional activities suggests that economic relations are far from being emptied of moral considerations. Moreover, it shows how economically relevant actions may be justified by referring to moral principles unrelated to the market logic of competition. Finally, respondents' replies reveal how reciprocal obligations may also be 
shoved aside completely in the name of non-instrumental friendship (Boltanski 1990; Kharkhordin 2005, 2009).

In the remaining text of this section, justification theory is first described in short and then, in the next section, applied to the Russian managers' interview data.

The basic idea of justification theory is that the normal, conventional course of action - for example, running a business - tends from time to time to drift into a dead end. Justification theory focuses on these 'critical moments' - crises, conflicts, and disputes - which force the disagreeing parties to argue and justify their actions by referring to 'a common good' recognized and accepted by both parties. ${ }^{7}$

In order to settle the dispute, the parties have to establish a principle of equivalence, against which the arguments presented in the dispute can be evaluated, and the 'worth' (grandeur) of the disputants can be measured.

Boltanski and Thévenot describe six different orders of worth, each of them referring to a different principle defining the 'worth', 'size', or 'greatness' (grandeur) of the disputing parties. They distinguish six common worlds based on these principles and on the beings (persons or things) that inhabit these worlds. ${ }^{8}$

First, in the market world, the greatness (grandeur) of an actor is defined by wealth and ultimately measured by markets. The greatness of a physician in this world, for example, could be measured by her commercial success in medical business. Second, in the industrial world, to continue the example, the same physician may be valued - irrespective of her commercial success - by her efficiency and measured in concrete terms, for example, by the number of patients handled per day. Third, in the domestic world, the greatness of the physician is evaluated by her position in the system of mutual dependency. Valued or 'worthy' in this world is one's trusted family doctor who has been treating all the members of the family for years and with whom one can always jump the queue to get an appointment. Fourth, in the civic world, a doctor is evaluated by her willingness to treat all patients equally as citizens. Fifth, in the world of fame, a great person would be a well-known media figure (such as Dr. Phil), whereas in the inspired world such a figure would be a genius surgeon who is the only one able to conduct certain operations because of her unique, God-given artistic capabilities. ${ }^{9}$

In this book the focus is mostly on the domestic and market orders of worth and the tensions between them. It is important to note that economic relations are not to be identified with market worth since a firm, for example, may be analyzed as a 'compromising device' between the market and industrial worth (Thévenot 2001). 
The originality of justification theory is that none of these moral orders are tied to particular social groups or superior to the others. The argumentation which is valid in one world may be out of place in another. Moreover, justification depends on the situation. The same person may, in the course of one day (or one hour), refer to different orders of worth to justify his actions. ${ }^{10}$

Since the orders of worth are equal, there is no privileged position for a critical sociologist à la Bourdieu - or any other outside observer. From this perspective the misrecognition game turns out to be part of the project that tries to reveal a deeper truth lurking behind the backs of the actors. Justification theory, on the contrary, analyzes the interviews as examples of the competence of actors to justify their actions.

In the next section we turn to the analysis of the empirical data, trying to follow the methodological principle of justification theory as summarized by Nicholas Dodier (1993: 567):

[L]et us take peoples' justifications seriously and study them in their plurality; let us observe how explanations are displayed, and accumulate the accounts people give of their actions; and let us examine the sense of justice they thereby express.

\section{Reciprocity and the domestic ethics of helping others out}

Though it is plausible to think of reciprocal obligation as a universal phenomenon in line with Alvin Gouldner, it is similarly likely that the actual expectations and forms of reciprocity are likely to vary between cultures. Edwina Uehara's review of the North American studies of reciprocity helps to place the observations of the previous section into a comparative context. ${ }^{11}$ Uehara's goal was to find out to what extent:

(1) [people] feel obliged to return support or assistance received from others and to act on this obligation; and (2) tend to resolve/give meaning to the reciprocity 'balance' in their relationships in a manner that avoids the interpretation that they are 'overbenefiting'.

(Uehara 1995: 488)

Uehara concludes that the studies reviewed support the idea of the existence of an obligation of reciprocity. But unlike it is postulated by the equity and utilitarian theories, in Western countries people seem in their reciprocal behavior rather to try to overbenefit a favor received that is, to pay their debts with interest - than to strive for balance or to take advantage of their exchange partner. Uehara's results are indicative 
of a context where the principles of market worth such as self-reliance and competitiveness are particularly valued:

All in all, the normative 'deck' [in Western countries] appears to be heavily stacked against the individual in need of assistance from others.

(Uehara 1995: 499)

Justification theory does not, however, confine various orders of worth to specific cultures, but sees them rather as universal points of reference whose weight may nevertheless differ depending both on cultural context and situation.

In Russian society, for example, reciprocal expectations exist in a context where - due to the Soviet heritage and probably the much longer domestic tradition of the Russian village community - people are bound to each other within a system of mutual dependency and thus accustomed to turning to each other for help in various daily life problems. Though this 'domestic' idea of helping others out is now being challenged by the introduction of market-based principles in post-Soviet Russia, it has not disappeared. More importantly, it can be referred to even in the context of an interview concerning business-related favors, as the following quote from a Russian owner of a successful IT company shows:

T: How and why does this [system of mutual favors] work?

P1: Because mother was reading us fairy tales in childhood. In the fairy tale Mashen'ka is running on a field, where there stands an oven. 'Take the pie out, it is burning,' the oven says. Mashen'ka takes the pie out of the oven. Then an apple tree asks: 'Shake me.' Mashen'ka shakes the tree. But the bad girl just runs ahead and does not help anyone. And she will end up badly. This is what we were taught in childhood, to share things with everyone, to cooperate, to help.

(general director, $\mathrm{p} 1$ )

The respondent is referring to a Russian fairy tale where the good girl Mashen'ka is helpful and gets rewarded at the end while things end up badly for the girl who does not help out other creatures. Many of Ledeneva's (1998) respondents recognized the same 'obligation to help'. Like our respondent quoted above Ledeneva herself describes this phenomenon, referring to another Russian fairy tale with similar contents:

As in the fairy tale about Ivan-the-Fool who, despite his grand mission to liberate Helen-the-Beauty, helped different creatures on his 
way, sharing food with them and saving their homes or lives. He would have had no chance in his fight with the Deathless (in Russian folklore a bony, emaciated old man, rich and wicked, who knows the secret of eternal life), but because every creature returned his favour, in their small ways in particular moments, in the end with their assistance he managed to kill the Deathless and marry the girl.

(Ledeneva 1998: 164-5, footnote 9)

Though these quotes may be read as examples of the reciprocal returning of favors, as Ledeneva remarks, here they will be interpreted as referrals to the importance of helping out others within a system of mutual dependency. Without this principle things will turn ugly for everyone: the pie will get burned and Mashen'ka will suffer. It is because of this systemic importance of mutual dependence that the one helping others out will finally be rewarded.

One of Ledeneva's respondents describes this domestic principle from a comparative perspective, contrasting it to the 'Western' world plagued by competition and self-reliance.

Western people, in contrast to us, are very independent. They rely on themselves and do not fancy helping out or accepting help from others. Russians assume that they can always ask for help and will help themselves. I am sure that if I ask I will be helped. And the other way around. If I am asked, I drop everything and help the other person, because I can imagine myself in his place. Indifference or refusal is a psychological trauma. I try not to refuse, giving out everything I can.

(Ledeneva 1998: 163)

This interview quote could be read as a stereotypical Russian selfidentification vis-à-vis a mythical and idealized Western business life. However, instead of this kind of interpretation or trying to find out whether the respondent above in actual fact helped others, in this text these kinds of expressions will be considered moral justifications of action.

In line with the evidence on the importance of mutual help drawn from our interviews, Vadim Radaev (1998: 15) describes 'the ethics of implicit contracts' based on the surveys conducted among Russian managers and entrepreneurs at the end of the 1990s. When asked if the entrepreneurs were willing to loan a considerable sum of money to a firm of their regular partner who was confronting financial 
difficulties, only one out five entrepreneurs responded negatively. Of the respondents, 27 percent would not require any interest, 25 percent would loan money on low interest, and only 3 percent on market interest (25 percent chose the option 'difficult to say').

Though the willingness to give discounts to trusted partners was probably partly related to the exceptional circumstances of the 1990s, by referring to the ethics of helping out some of our respondents still recognized the mutual dependence of people - and particularly the dependence between the members of one's own personal network. Recognizing and sharing this moral principle means, first, that in Russia it is easier to ask for help and favors than in a context emphasizing competition and self-reliance. Second, it means that a request for help is more difficult to turn down in Russia by saying that 'it is not my business'.

At the risk of exaggeration, one may claim that while asking for help is interpreted in 'Western' culture as a sign of weakness, in Russia turning down a request for help from one's network member is a sign of rude, uncivilized behavior. One of our respondents (development director, p5), for example, having criticized at length the barter logic implied in our question on reciprocity, summarized that the topic of discussion was related, rather than to the professional sphere, 'to the worldview' (eto skoree vsego otnositsia $k$ mirovospriiatiiu).

If this hypothesis is valid, we can better understand the replies of our respondents about the variations and denials of reciprocity as indicative of a context in which 'owing favors' is common and allowed. Where problems are often solved 'with a little help from my friends,' the pressure to reciprocate may be less stringent than in a context stressing the individual's capacity to do it 'my way'.

If we think of the reciprocal expectations as a cohesive force in networks (as a kind of 'social glue'), the pressure on self-reliance and immediate reciprocating in fact tries to dissolve this glue by a quick and full return of favor. ${ }^{12}$ The weaker pressure on reciprocation goes hand in hand with the tendency to help others out, the importance of obshchenie, and the maintenance of network ties.

Nevertheless, referring to the ethics of helping out does not mean that it is applied in practice automatically in all circumstances. Instead, its application is likely to depend on the specific situation and person. Rather then describing Russian IT professionals as altruistic actors always ready to sacrifice their own interest, the analysis of this section has tried to illustrate the tensions between the new market-based logic emphasizing independence, competitiveness, and self-reliance, and the 
traditional domestic logic of helping out others in a system of mutual dependency.

\section{Brokerage}

Q: Have you sometimes exchanged useful contacts through your acquaintances? For example, have you recommended your acquaintance who can help you with a question you cannot?

P6: Of course. It is an element of everyday communication (eto kak element povsednevnogo obshcheniia). It happens very often beginning with small details. It is difficult to tell examples, because it is so self-evident.

(marketing director, p6)

This section considers middlemen or brokers as another important social mechanism regulating transactions in personal networks. Brokers may, among other things, create trust between network members, transmit and evaluate resources circulating in networks, and enlarge the networks through the introduction of new members. In addition to these connective and collaborative functions, brokers may also try to use their position as middlemen between unconnected network members to their own advantage.

According to our respondents, the inclination to use third persons in transmission or evaluation of resources is a conventional and routinized way of acting in the Russian business environment: ${ }^{13}$

According to my personal experience I can here [in Russia] freely phone a quite distant acquaintance, that is, someone whom I know well enough to phone, and ask him a favor or propose something. In Germany [where the respondent had worked] this is not as usual.

(general director, $\mathrm{p} 4$ )

Recent research has emphasized that brokers do not only pass on resources but also participate actively in the process by adapting and refining them (Mustikkamäki 2008; Sverrisson 2001; Obstfeld 2005; Obstfeld and Borgatti 2008; see also Gould and Fernandez 1989). ${ }^{14}$ This active involvement is particularly important in the field of information technology where the transmission of information is often accompanied by its sorting, filtering, and analysis.

The first part of this section discusses the dividing and connecting aspects of brokerage on the basis of Ronald Burt's and David Obstfeld's 
theorizing. The remaining part focuses on the connecting and collaborative aspects of brokerage, illustrating them on the basis of our empirical data.

\section{The broker as divider and as connector}

One of the central ideas concerning brokerage is the theory of structural holes by Ronald Burt (1992). According to David Obstfeld (2005) Burt's theory is based on a variant of Georg Simmel's idea of the tertius gaudens broker (third who gains), where the third person in a triad takes advantage of the missing contact between the two other actors:

He [Burt] argued that social networks rich in structural holes present opportunities for using a tertius gaudens strategy, by which an actor positioned between two disconnected parties can manipulate or exploit those parties to the actor's benefit.

(Obstfeld 2005: 103)

Though Obstfeld notes that Burt has also addressed a broader variation of triadic behaviors, structural hole theory concentrates on the separation of actors suggested in Simmel's original usage. Burt's theory is marked by competition, control, and conflicts, and his tertius gaudens broker attempts to profit from his position by keeping the triad's other parts separate.

Unlike Burt's, Obstfeld's approach to brokerage builds on the tertius iungens (third who joins) ${ }^{15}$ - a non-competitive and non-adversarial 'behavioral orientation toward connecting people by either introducing disconnected individuals or facilitating new coordination between connected individuals' (Obstfeld 2005: 102; see also Obstfeld and Borgatti 2008). ${ }^{16}$

Obstfeld (2005) distinguishes four types of brokerage. The first type (conduit) refers to coordination of action or information between parties who have no immediate prospects for direct introduction or connection. The second type (tertius gaudens) contains Burt's theory of structural holes. The third type (brief tertius iungens) introduces or facilitates ties between parties where a continuing coordinative role is unnecessary, diminishes in importance, or simply is not offered. The fourth type (sustained tertius iungens) introduces or facilitates interaction between parties while maintaining an essential coordinative role.

Obstfeld's idea of tertius iungens does not, however, exclude the presence of structural holes - which would lead to completely closed 
networks - because the introduction of new members to the network by a cooperative broker may, together with closing old structural holes, also create new holes.

In brief, the viewpoints of Burt and Obstfeld shed light on the two sides of brokerage, competition and collaboration, both of which merit attention. In this section the focus is, in line with the main emphasis of this book, on the latter, particularly on the role of brokers in connecting, transmitting, and evaluating resources circulating in the personal networks.

The remaining two sections do not aim at a fine-grained conceptual analysis of different brokerage types or functions but rather try to illustrate the significance of middlemen in the Russian IT business through the examination of our empirical data. Particular focus is placed on the brokers' role in recruiting employees, since competent staff was the most valuable and scarce resource in the St. Petersburg IT industry at the time of our interviews.

\section{Brokers as connectors}

I simply have a huge database [of connections] in my head. Probably not in details, but I know how to connect people who can help each other.

(project leader, p26)

According to our respondents, brokerage chains and triads were common in IT business. The inclination to turn to middlemen for help was illustrated in the expressions used by our respondents, where the instances of brokerage were described as, for example, 'self-evident' or were considered part of 'human communication' (chelovecheskoe obshchenie), and contact information was actively transmitted within one's personal network:

In my circle of communication ( $v$ kruge moego obshcheniia) we usually let each other know about useful contacts. All colleagues in this circle think like this: 'I got to know an interesting person and for you it would be useful to talk with him'.

(general director, $\mathrm{p} 7$ )

Through brokers the network ties transferred information about a wide variety of resources such as technologies, markets, and competition. Though contacts with customers were a heavily contested resource, 
even they were at times transmitted from one firm to another provided that the firms were not active in the same markets:

Q: Have you sometimes exchanged useful contacts through acquaintances?

P10: Of course. This is banal: two weeks ago I got a phone call from my acquaintance who is also working in the IT industry. His firm has a slightly different specialization. He was contacted concerning a project which is our specialty but not theirs. So he transmitted a contact with a potential customer.

(director, p10)

In the basic 'brokerage triad' between the donor, broker, and receiver, three different but interrelated ties will be born, in which the broker may function either as the third person introducing the donor and the receiver, or the guarantor of their interrelation, or both. In some cases these brokerage chains could grow long and complex. One of the respondents (director, p39) told about a phone call he got on a Sunday from his colleague 'from a friendly company'. This colleague needed to find a programmer for his project that same day. Our respondent asked the colleague to describe the requirements of the job and turned then to his personal contact notebook which contained almost 200 names. The second broker in this transmission chain was our respondent's acquaintance working in another firm, whom our respondent phoned explaining the problem:

He [the respondent's acquaintance] said: 'This is not my field. Phone N. N'. I phoned N. N. who said: 'Yes this person exists but he is now devil knows where. You cannot reach him by phone, but he can be found through a third person'. (...) Finally, the person was found on Sunday, after three hours of searching.

(director, p39)

This quote is illustrative both of the dense networks between the managers of the St. Petersburg IT companies and of the speed and efficacy of personal networks, but most importantly, of the inclination and willingness of all links in the search chain - including at least four professionals - to work as middlemen. This inclination is related to the ethics of helping out described in the previous sections and 
forms an important aspect of the functioning of personal networks in Russia.

\section{Brokers as evaluators}

Brokers were central not only in transmitting and connecting, but also in evaluating various resources circulating in the networks. Among the most valuable and scarce resources were competent employees, whose assessment through networks will be at the center of this section.

The particular significance of personal evaluations and recommendations in Russia may be understood against the lack or distrust of formal means and institutions of evaluation. Overcoming this distrust with the help of personal network ties was underlined by a 40-year-old company director who had conducted a survey about how customers had found their company. He illustrates the significance of trusted third persons with the following example:

If a person tells his friend that I've bought a TV set at this specific firm, his friend will go there automatically, without thinking, just trusting his friend. Even though this person may have bought his TV set there by chance, his friend will anyhow automatically also buy his TV set there. Provided, of course, that everything was OK with this firm. His friend will go there and the friend of his friend, and this chain will work on and on. [According to our customer survey] a significant percentage of our clients come here because of recommendation from somebody. Moreover, when there is a personnel change in a [customer] company, the new employee will first see with whom the company has worked before. And if they've been happy, they will continue to work with us.

(director, p22)

The need for recommendations from a third person was even more acute in the field of IT services, where defining the quality of the services, products, or labor was a much more complex process than evaluating the quality of TV sets. Though international certification standards such as ISO9000 and CMM were referred to by some of our respondents, ${ }^{17}$ only a minority of small- or medium-sized firms have been granted these certifications.

The remaining text of this section focuses on the use of brokers in recruiting personnel which, at the time when our interviews were conducted, was the main problem for St. Petersburg IT firms. Despite 
high-level theoretical knowledge, the graduates from the local universities lacked practical experience of, say, project management or language skills necessary for a successful career in the IT business, and the evaluation of their de facto capacities was crucial for the employers.

When assessing the potential candidates for recruitment all information available was used, including formal applications and written testimonials from previous workplaces. However, written testimonials could have strings attached. A good testimonial, for example, could turn out to be an attempt to save the face of an incompetent employee and avoid problems which would have resulted from his firing:

[Y]ou have to fire a person. He says OK, gets up, leaves his resignation of his own free will and saves his face. You will save his face. He could say that I won't resign, fire me according to the laws. He takes the issue to court after which the real show begins. He will say that you are paying salaries under the counter. And you will say that I will send 13-year-old hooligans to your home to explain to him where to look for his salary (...) who needs this? You will write him a letter of recommendation (...) and he continues on the markets, shows the letter.

(general director, p3)

Moreover, in a formal testimonial the image given of the evaluation target is positive and flawless. The possible failures, conflicts, and other shortcomings at work have been excluded, whereas in an informal recommendation both pros and cons of the target can be dealt with.

Because a testimonial as a rule is written to an anonymous reader, it implies a different kind of responsibility than an informal recommendation given in a brokerage chain to an old acquaintance or friend:

If for example one of my former employees is looking for job in some firm and asks for a recommendation (...) if he does not ask anything supernatural, I'll write a recommendation regardless of how our work relationship ended. And I don't feel any responsibility for it to other people (...) If I recommend to a friend, good acquaintance or my partner a person whom I know personally, then I will bear a certain responsibility for it. And therefore I think ten times, I weigh everything before I will give a recommendation. These are completely obvious things.

(general director, $\mathrm{p} 4$ )

Therefore, when possible, an attempt was made to check the information of the formal testimonial against the evidence obtained from 
trusted third persons. In a typical case, the new employer would contact the former employer of the applicant to inquire about the background, trustworthiness, and competence of the employee:

If I see from the application that the applicant has worked, e.g., with Volkov [a well-known St. Petersburg IT entrepreneur - name has been changed], and I am not hiring a cleaner but a programmer, I will certainly phone Volkov and ask: Gennady Viktorovich, you had soand-so working for you. What can you tell me about him? 'Nutcase' (pridurok). Thanks a lot, Gennady Viktorovich.

(general director, $\mathrm{p} 3$ )

In this example the written testimonial was bypassed in favor of a personal recommendation which was not made public: unlike formal evaluations, informal ones are often made orally and the persons evaluated do not necessarily know about the contents of these assessments or even about their existence.

Checking the background of the applicant over the phone was a common way of inquiring about the applicant's character and competences. During one such conversation concerning an applicant, the advice given was 'to chase him out with a broom' (project leader, p24).

However, informal recommendations were also evaluated critically and were cross-checked with different sources:

If I see from the applicant's CV that he worked in a particular firm, it is very important for me to be able to phone some acquaintance in this firm and ask how things are with this person. Why did he leave the firm, what he was unhappy with, what are his weak and strong points? It is of course very important to talk directly with the employee because the information received from a third party is not always objective. Thus one shouldn't blindly trust some recommendations but always communicate directly with the person in question.

(technical director, $\mathrm{p} 11$ )

Moreover, neither good informal recommendations nor testimonials will secure a job if the candidate does not pass the formal tests required, for example, to land a programming job.

In one company the applicants had to fill in a form where they were asked if they had acquaintances in the company. In the case of a positive reply, the recruiters turned to this acquaintance for additional 
information ranging from the applicant's professional competence to a detailed description of his personality: 'This person is psychologically unstable. I studied with him at school and he used to throw paper balls at the teacher' (PR-manager, p2).

In another company recruiting through networks was formalized in the form of a bonus paid to employees for bringing in a new worker. In this case the company's employee functioned as a broker responsible for the new candidate:

If I recruit staff through my own employees the one who brings in a new person is personally responsible for him to me. The employee is still my subordinate and thereby bound to me 'by blood' (po krovi poviazan). If I recruit an employee through acquaintances and am unsatisfied with him, I am forced either to cut my relations with this acquaintance or carry that burden (derzhat' kamen' za pazuhoi) for the rest of my life.

(general director, $\mathrm{p} 7$ )

While employers tried to evaluate the competences of the potential employees, the employees themselves were simultaneously turning to third persons to evaluate the quality of the employers. Because of the mobility of the workforce and the relatively small size of St. Petersburg markets, the reputation of both employers and employees spread quickly through networks:

Q: How important are social networks to the formation of a person's reputation?

P11. Extremely important. Particularly important is the lack of negative information. Negative information about the company or the director may stain the project right away. It will be more difficult to find staff if it is commonly known that the company does not treat employees fairly. This information will quite soon become common knowledge.

Q: And will be particularly damaging for recruiting?

P11: Of course. Such negative information is spread primarily through acquaintances. It is not usually published and therefore you can find negative information only through acquaintances.

(technical director, $\mathrm{p} 11$ )

In sum, the role of brokers was central both in introducing new members to personal networks and evaluating the resources circulating in 
them. Inclination to turn to brokers and willingness to act as one were marked features of the Russian managers' activities. The role of brokers was further emphasized by the lack and distrust of formal systems of evaluation and was facilitated by the relatively small circles within the industry.

\section{The mixing of personal and professional spheres of life}

This section describes how the personal and professional spheres of life get intertwined in Russian managers' networks. This mixing was due to both the historical development of the Russian IT field discussed in previous chapters and more general cultural factors related to the Russian workplace. Once established, this intertwining affected the ways transactions were conducted.

The main focus of this section is on strong ties, particularly the ties of friendship, and their mixing with the economic activities of our respondents. The remaining text analyzes both the advantages and the problems and tensions caused by the efforts to combine friendship and business.

\section{The role of strong ties in the Russian ICT business}

As described in the previous chapter, for a Russian entrepreneur just starting out it was a natural choice to turn to personal network members such as kin, family, or friends in order to start up a firm, arrange starting capital, and recruit personnel (cf. Oleinik 2004: 88). Several of our respondents had indeed built their companies upon this kind of 'strong ties' (Granovetter 1973) which in itself had contributed to the dissolving of the boundary between personal and professional spheres of life.

The roots of this mixing can be traced back to the cultural aspects of the Soviet workplace, which regulated most aspects of the citizens' daily life, including those which in Western countries were considered 'private'. It is not coincidental that the Soviet workplace was sometimes dubbed 'second home' (vtoroi dom) by workers and the relations within the 'labor collective' (trudovoi kollektiv) in many ways mixed with other aspects of life.

Though in many ways different from the Soviet era, some of the cultural meanings and practices have been carried over to post-Soviet workplaces, and studies of the workplace as the nexus of social life in post-Soviet Russia have found a strong overlap between the personal and public spheres (Lonkila 1998, 2010; Lonkila and Salmi 2005). 
Similar to these studies, our data illustrates how having people at work who were not only colleagues but also kin, friends, or good acquaintances extended work-connected favors to other areas of life. ${ }^{18}$ In the company of one of our respondents, which belonged to the group of the most central software firms in St. Petersburg it was, for example, a customary practice to borrow discount cards for shopping from one's colleagues:

I guess that every person has some kind of discount cards for various shops, furniture, home appliances and so on. There are a lot of these cards but everyone does not have a card for every shop. Before we had a quite common practice that an employee planning to buy a bed, for example, would turn to the management asking information about who in our firm would have a discount card for Maksidom. And often it happened that there was such a person: 'Yes, Boris, go to the office 402, your card is waiting for you'. At some point of time we understood that we had to organize this information because there were so many letters coming in. Thus we published information in our company intranet about all cards owned by the firm employees, naturally hoping that no single person would be too much bothered.

Another respondent (project leader, p26) whose girlfriend worked for the same company turned to his boss in order to find a loan to buy an apartment. Other examples of mutual help crossing the borders of the professional and personal spheres of life, such as borrowing a colleague's car or loaning money, abounded in the interviews and were likely to affect the nature of our respondents' economic activities.

\section{The importance of friendship}

In addition to showing up in the respondents' life stories recorded in the interviews, the mixing of close relationships, particularly friendship, with business ties also emerged in the online survey data (see section on data collection). Quite surprisingly, given the instrumental formulation of the survey questions, ${ }^{19}$ the characterizations by Russian respondents contained a lot of morally and emotionally loaded descriptions, for example, 'friend and colleague, consults me on work matters', 'boss and a good friend', 'we are good family friends, we spend spare time together, play football', 'my boss and simply a good person', 'good and understanding friend, we are working on some projects together', and so forth. Particularly interesting was the share of characterizations 
describing the emotional closeness between the respondent and his network members or the moral qualities of the latter.

These characterizations suggest that friendship ties were strongly present also in the professional life of the Russian IT managers. This observation was supported by the fact that, of all social ties useful for business or career reported by the respondents, 22 percent were friendship relations. Moreover, 62 percent of all respondents recorded at least one friend in their personal network. ${ }^{20}$

In themselves, these figures seem to testify to the importance of friendship relations - and thus also to the mixing of professional and personal spheres of life. But we also conducted an analysis of all relationship descriptions that implied a crisscrossing of the borders of personal and public spheres of life. Because the survey question inquired about the help received in the context of professional activities, each instance of friendship or kin ('pleasant acquaintances' - priiateli and acquaintances were not included) was counted as an instance of this blurring of boundaries by definition. To them were added other kinds of descriptions in which boundary crossing was clearly indicated, such as 'work and personal relationship', 'more than just a director', 'we play football together', and so forth. Altogether 108 such descriptions (31 percent of all ties) were found, lending further credence to the mixing of the spheres.

Finally, when 40 network structures reported by the respondents were selected for closer inspection, the role of friendship in the support networks of the Russian managers turned out to be even more vital. ${ }^{21}$ When the number of ties involving at least one friend at the other end (or both ends) was calculated relative to all ties in the network, the average indication of the structural importance of friends in the networks was on average around 60 percent, reaching 100 percent for nine networks.

This is not to say that all St. Petersburg firms are populated by kin and friends or that friendship ties in business are necessarily only a Russian particularity. On the contrary, several studies (e.g. Dulsrud and Grønhaug 2007; Halpern 1994; Ingram and Roberts 2000; Kadushin 1995) point to the importance of the role of friendship also in Western economic life. ${ }^{22}$ The mere number of the relations, however, is not enough to make conclusions about the significance of these ties, since the meaning of friendship varies between cultures (Fischer 1982; Castrén and Lonkila 2004; Kharkhordin 2005). In other words, Russian friends may expect different kinds of behavior from each other than American or Finnish friends. For instance, helping out a friend seems to 
be constitutive of the Russian friendship relation to a different degree than in Finland. ${ }^{23}$

Having friends as colleagues, bosses, business partners, principals, or clients may be both a blessing and a curse. The remaining text of this chapter analyzes the pros and cons of combining business and friendship.

\section{Combining friendship with business}

When we asked about possible conflicts between friendship and business, managers' replies revealed the complex relation between these two kinds of social tie. ${ }^{24}$

First, some respondents distinguished strictly between friendship and business ('the best way to get rid of a friend is to lend him money'). In this case the worlds of friendship and business were clearly separated (Dulsrud and Grønhaug 2007).

Second, respondents emphasized the positive aspects of friendship for business. The trust inherent in friendship can, for example, help in work tasks which otherwise might require complicated arrangements. In cases of possible conflict, finding a compromise with a good friend might be easier because of a common past and shared worldview.

Third, respondents questioned - similar to the replies to the question on reciprocity - the generalization implied by the question. In this case respondents started reflecting upon the combination of friendship and business in relation to the situation and person in question. Thus, the reply to the question of whether it is possible to combine friendship and business would be 'that depends on the friend and the situation'. A good friend might be, because of his disorganized character or other features, completely unsuitable for business:

P5: I find it is stereotypical to think that friendship and work fit poorly together. There are many practical considerations related to this. On the other hand we have live examples of how good friends run businesses together very successfully. I think this depends a lot on the people.

Q: In which way?

P5. Punctuality, organized character. A person could be your friend but not necessarily a well-organized and good business partner.

(development director, p5)

Fourth, the success of the 'marriage' between business and friendship was considered to depend on the sequential order in which they were 
born. As described above, in many cases firms were established on the basis of an existing friendship relation or network:

Q: Do you know if the owners of your firm are friends?

P6: Yes.

Q: Were they friends already before starting business?

P6: Yes. This is not an individual example. For instance the firm of my husband was established originally by a small group of enthusiasts (...) they all know each other and are friends.

(marketing director, p6)

Since friendship contains elements, such as trust, which are beneficial in running a company, building a firm upon a circle of friends, kin, and acquaintances was not an uncommon way to establish an IT business in St. Petersburg during the 1990s. But sometimes these two ties may come into conflict, as in a case where friends disagree upon an important decision:

Q: How in your opinion do business and friendship fit together? Have you been in situations where there was a conflict between friendship and business?

P1: I have been lucky not to be in such a situation. Though the present managing director and partner is our good friend. But I know several cases where friendship and business disturb each other.

Q: Why?

P1. Because often it is a question about a decision made by one person. (...) In business there are situations when one person has to be leader and sometimes this causes conflicts. In friendship it is difficult to be a leader.

(general director, $\mathrm{p} 1$ )

In the worst possible cases, the emerging disagreement may end with the destruction of the friendship tie or business, or both. It may, to take a concrete example, be a rational decision to fire an incompetent business partner-friend.

Generally I think that one should not work with friends. If you, for example, get into a situation, and these situations occur often, when you will have to fire your best friend (...) I got into exactly such a situation. 
One of our respondents referred to business as an ongoing 'test' (ispytanie) for friendship. In his opinion, friends doing business together have to be on guard all the time, because of the fragility of this combination:

Q: How in general do friendship and business relate to each other? Have you been in a situation where they got into conflict? P10: (...) business is quite a test for friendship (ispytanie dlia druzhby). Many passed the test but many did not, and either friendship or business crashed. (...) it is a difficult test (tiazheloe ispytanie). I have at the moment no conflicts between friendship and business, but if you are conducting business with friends you have to be constantly ready that it will lead to conflict. The same with family relations. Some think that it is a bad idea to conduct business with your wife. But there are situations where it works well.

(director, p10)

The respondent does not detail the nature of the test. But this could mean, for example, giving a customer-friend credit without guarantees, or not demanding written, formal contracts which could be interpreted as a lack of trust between friends.

Unlike in previous examples, friendships could also be built upon already existing business relationships. Some respondents considered this variation easier than the preceding one:

In my opinion if a good business exists, a friendship will be born. The other way around is rarer and that's why I try to avoid building business with friends.

(general director, $\mathrm{p} 7$ )

Another respondent supported this reflection by warning against starting a business with someone only because he is a friend. It may be pleasant to drink beer with a friend, but besides this, he may turn out to be a useless business partner:

But the other way around [turning business into friendship] - as much as you like. You can have a great time working together and in addition you may also spend free time together.

(director, p39)

This difference may be due to asymmetric dynamics of transformation of the ties. Trying to turn a business relationship into friendship, 
the first type of tie is more or less conditioned by calculative rationality. Dissolving these conditions may happen by giving up the formal practices step by step ('I trust you as an old buddy so I won't ask for guarantees for this loan'). In this case a limited tie will be gradually transformed into a more diffuse one.

The reverse transformation will impose limits on the diffuse friendship tie (for example, the friends will be forced to formalize their relationship in a written contract). Sometimes this may lead to complete revaluation of the relationship and breaking up of the friendship.

Combining friendship and business ties may thus strengthen a relationship but may also create tensions. For our online survey respondents, these tensions are all the more serious considering both the long duration of the reported friendship ties in the web survey data - 19 years on average - and the particular role of friendship in Russian culture. ${ }^{25}$

In all, this chapter analyzed the functioning of social mechanisms and practices governing network exchanges in the Russian software industry. It showed how economically relevant resources are not only channeled and evaluated through middlemen, but that transactions also include a moral domestic element alternative to market-based logic. Combining this domestic logic, ties of friendship, and the new world of market competition is a potential source of conflicts between the two sometimes-contradictory worlds.

The chapter also illustrated the complex interplay of the Soviet past and the post-Soviet present addressed in previous chapters. The role of strong ties, for example, cannot be only conceived of as a Soviet legacy since it was also a solution to the problem of trust in the turbulent conditions in the 1990s in Russia.

In sum, the present-day Russian market economy seems to lean in many ways on the functioning of personal networks and the domestic logic of action. The next chapter will analyze if this could be a basis for generalizing the value of particular and trusted links to any potential new relationship as suggested by Luc Boltanski and Ève Chiapello in their account of the 'new spirit of capitalism'. 